\title{
What can genomics tell us about the success of enhancement programs in anadromous Chinook salmon? A comparative analysis across four generations
}

Charles D. Waters ${ }^{\mathrm{a}}$, Jeffrey J. Hard ${ }^{\mathrm{b}}$, Marine S.O. Brieuc ${ }^{\mathrm{a}}$, David E. Fast ${ }^{\mathrm{c}}$, Kenneth I. Warheit ${ }^{\mathrm{d}}$, Robin S. Waples ${ }^{\mathrm{b}}$, Curtis M. Knudsen ${ }^{\mathrm{e}}$, William J. Bosch ${ }^{\mathrm{c}}$, and Kerry A. Naish ${ }^{\mathrm{a}}$

\author{
${ }^{a}$ School of Aquatic and Fishery Sciences, University of Washington, 1122 NE Boat St., Seattle, WA 98105, USA \\ ${ }^{\mathrm{b}}$ National Oceanic and Atmospheric Administration, Northwest Fisheries Science Center, \\ 2725 Montlake Blvd. East, Seattle, WA 98112, USA \\ ${ }^{c}$ Yakama Nation Fisheries, P.O. Box 151, Toppenish, WA 98948, USA \\ ${ }^{\mathrm{d}}$ Washington Department of Fish and Wildlife, 600 Capitol Way North, Olympia, WA 98501, USA \\ encorh Consulting, 2623 Galloway SE, Olympia, WA 98501, USA
}

Authors of correspondence: Charles D. Waters cwaters8@uw.edu, Kerry A. Naish knaish@uw.edu

This paper was presented in an invited session entitled; Genomics for improved fisheries management and conservation: have the promises been fulfilled? at the 7th World Fisheries Congress which was sponsored by the OECD Co-operative Research Programme on Biological Resource Management for Sustainable Agricultural Systems, whose financial support made it possible for the invited speakers to participate in the Special Session.

The opinions expressed and arguments employed in this publication are the sole responsibility of the authors and do not necessarily reflect those of the OECD or of the governments of its Member countries.

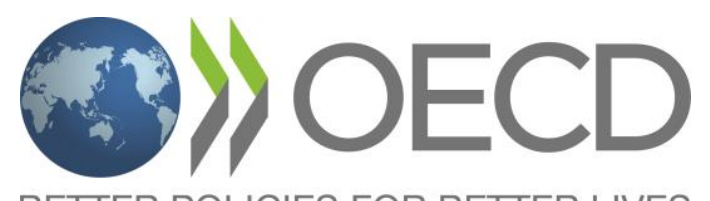




\begin{abstract}
Population enhancement through the release of cultured organisms can be an important tool for marine restoration. However, there has been considerable debate about whether releases effectively contribute to conservation and harvest objectives, and whether cultured organisms impact the fitness of wild populations. Pacific salmonid hatcheries on the West Coast of North America represent one of the largest enhancement programs in the world. Molecular-based pedigree studies on one or two generations have contributed to our understanding of the fitness of hatchery-reared individuals relative to wild individuals, and tend to show that hatchery fish have lower reproductive success. However, interpreting the significance of these results can be challenging because the long-term genetic and ecological effects of releases on supplemented populations are unknown. Further, pedigree studies have been opportunistic, rather than hypothesis driven, and have not provided information on "best case" management scenarios. Here, we present a comparative, experimental approach based on genome-wide surveys of changes in diversity in two hatchery lines founded from the same population. We demonstrate that gene flow with wild individuals can reduce divergence from the wild source population over four generations. We also report evidence for consistent genetic changes in a closed hatchery population that can be explained by both genetic drift and domestication selection. The results of this study suggest that genetic risks can be minimized over at least four generations with appropriate actions, and provide empirical support for a decision-making framework that is relevant to the management of hatchery populations.
\end{abstract}

\title{
Introduction
}

Enhancement, the release of cultured organisms to increase population abundance, is an important fishery management tool (Lorenzen et al. 2010). But genetic risks associated with artificial propagation are well known and may compromise the wild populations that enhancement is intended to support (Naish et al. 2008; Laikre et al. 2010). Supportive breeding programs are a form of enhancement used extensively in the management of Pacific salmon in North America. Such programs aim to increase population sizes by rearing a fraction of juveniles in captivity and then releasing them into the natural environment along with their wild-born conspecifics (Ryman \& Laikre 1991). Concerted efforts have been directed at mitigating the effects of domestication selection, genetic drift and inbreeding (Mobrand et al. 2005) associated with these programs, because in many cases populations have not recovered and cannot support sustainable fisheries (Naish et al. 2008; Beamish et al. 2010; Scheuerell et al. 2015). Practical recommendations to mitigate genetic risks have focused on theoretical models that examine the influence of gene flow in reducing divergence between cultured and wild populations (Duschene \& Bernatchez 2002; Ford 2002; Baskett \& Waples 2013). Specifically, the intentional use of naturalorigin broodstock in the creation of the hatchery population in each generation may reduce risks, especially when gene flow from the hatchery to the wild population is limited (Mobrand et al. 2005). Such "managed gene flow" has seen widespread adoption in the Pacific Northwest of the USA (Paquet et al. 2011), but few practical examples on their efficacy exist.

An ideal way to test whether managed gene flow is effective at reducing genetic divergence between hatchery and wild populations is to empirically compare cultured populations with and without gene flow. Such a comparison would provide results on the range of possible outcomes of these management approaches, and would be especially informative if conducted longitudinally. The use of population genomic approaches provides a way to survey temporal changes in genetic divergence, to measure the rate of change with each generation since founding, and to identify factors driving divergence. We previously conducted such a study in two populations of Chinook salmon (Oncorhynchus tshawytscha) released from a hatchery on a tributary of the Columbia River (Waters et al. 2015). Both hatchery populations were founded from the same source population; however, one population remained integrated with the wild and used only wild-born broodstock in each generation, while the second hatchery population was maintained separately and received no gene flow from the wild. Our earlier results over three generations revealed little change in the integrated line compared to the founding population. Most of the genetic divergence in the segregated line could be attributed to genetic drift, but there was also evidence for directional selection at specific locations in the genome. However, it is unclear over how many generations managed gene flow may be effective at mitigating genetic risks, because processes occurring in the wild could mitigate or exacerbate the effects over time (Ford 2002; Baskett \& Waples 2013). Here we aimed to test whether the use of natural-origin broodstock was effective at reducing divergence over several generations by extending our earlier study for an additional fourth generation.

\section{Materials and Methods}

A spring Chinook salmon hatchery program was initiated in 1997 at the Cle Elum Supplementation and Research Facility (CESRF, Fig. 1) to supplement the declining upper Yakima River Chinook salmon population while minimizing possible genetic and ecological risks associated with supportive breeding. Local, wild adults were collected for broodstock from 1997 to 2002 as they passed the Roza Dam Adult Monitoring Facility (Roza Dam, Fig. 1). Adults were then transferred to CESRF and held until spawning. Eggs and juveniles were reared in the hatchery for approximately 18 months before they began their migration to the ocean. Adult hatchery fish first returned to the Yakima River in 2001 and were allowed to spawn naturally. In 2002, both wild and hatchery-origin adults were spawned at CESRF to create two contrasting hatchery lines. The integrated (INT) line is derived only from wild or natural-origin adults, and all fish from this line are 
allowed to spawn naturally. Here, natural-origin fish are those that were born in the river but may have some hatchery ancestry. The segregated (SEG) line, however, uses only hatchery-origin broodstock, and no fish can spawn in the river.

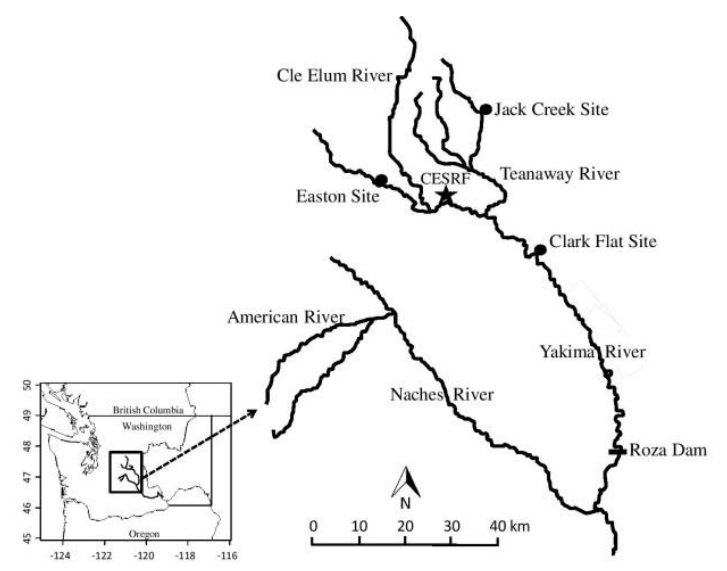

Figure 1. From Waters et al. (2015). Map of the Yakima River system. The upper Yakima Chinook salmon population is the target of the Cle Elum Supplementation and Research Facility (CESRF). All returning adults are sampled at Roza Dam and allowed to spawn naturally (natural origin and integrated line fish) or are removed from the system (all segregated line fish). Spawning and rearing for the hatchery lines occurs at CESRF. Prior to outmigration in spring, juveniles are transferred to the Easton, Jack Creek, and Clark Flat acclimation sites, where they are held for approximately two months before volitional release.

Tissues for DNA were sampled from adults of both hatchery lines in 2014 during spawning at CESRF and stored in 100\% ethanol. These adults represent the fourth $\left(\mathrm{F}_{4}\right)$ generation of each line. DNA was extracted using DNeasy Blood \& Tissue kits (Qiagen, Valencia, CA, USA) following the animal tissue protocol. Restriction site-associated (RAD) libraries (Baird et al. 2008) were prepared using the restriction enzyme SbfI and sequenced on the Illumina HiSeq 2000 platform with 36 individuals per lane. All raw RAD sequences from the $F_{4}$ generation were combined with raw data from our previous comparative analysis $\left(\mathrm{P}_{1}\right.$ founders and $\mathrm{F}_{1}-\mathrm{F}_{3}$ generations, Waters et al. 2015). Filtering and genotyping were performed following Waters et al. (2015), with two additional steps to improve data quality. First, loci were removed if more than $50 \%$ of individuals in any population were not genotyped. Then, loci were removed if they did not meet Hardy-Weinberg equilibrium conditions $(q$-value $<0.05)$ in more than one population, as determined by the Monte Carlo procedure with $1 \times 10^{5}$ permutations in the R-package adegenet (v. 1.3-9, Jombart 2008). $Q$-values were computed using the R-package qvalue (v. 1.28.0, Storey 2002).

As the aim of the present study was to extend previous comparisons between the integrated and segregated hatchery lines by another generation, genetic change was evaluated using the same methods described in Waters et al. (2015). Population-level genetic change between each generation of the hatchery lines was evaluated using measures of $F_{S T}$, computed in Genepop (v. 4.1, Raymond \& Rousset 1995), and a discriminant analysis of principal components (DAPC), conducted in the R-package adegenet. The relative effect of genetic drift within each hatchery line was determined using estimates of effective numbers of breeders, $\mathrm{N}_{\mathrm{b}}$. Temporal and linkage disequilibrium (LD) estimates of $\mathrm{N}_{\mathrm{b}}$ were computed with $\mathrm{N}_{\mathrm{E}}$ Estimator (v. 2.01, Do et al. 2014) using only four-year-old adults, which represented a single cohort of individuals. Steps taken to reduce potential bias in $\mathrm{N}_{\mathrm{b}}$ estimates due to selection, overlapping generations, and fluctuating population size were identical to those of Waters et al. (2015). Lastly, loci and genomic regions exhibiting signals of diversifying selection in the hatchery lines were identified using three independent tests: $F_{\text {TEMP }}$ (Therkildsen et al. 2013), Bayescan (Foll \& Gaggiotti 2008), and a sliding-window approach (Brieuc et al. 2015; Waters et al. 2015). We focused on loci and regions that were identified by multiple tests and were divergent across multiple generations.

\section{Results}

Tissues from 72 individuals ( 36 from each line) were sequenced from the $\mathrm{F}_{4}$ generation. The raw data was combined with RAD sequences from the previous generations and filtered, yielding 9266 bi-allelic RAD loci with minor allele frequencies $>0.05$ in at least one population and less than $50 \%$ missing genotypes within each population. A total of 465 individuals from the five generations were genotyped at $>50 \%$ of these loci and retained for analyses (Tables S1, S2). Tests of HWE identified 158 loci that significantly deviated from expectations in more than one population. Following removal of these loci, the final data set comprised 9108 loci (Table S1), including 4214 loci that aligned to the Chinook salmon linkage map (Brieuc et al. 2014). Population-level divergence of the two hatchery lines followed previously documented trends (Waters et al. 2015). Values of pairwise $F_{S T}$ between the lines and the $\mathrm{P}_{1}$ founders was approximately four times higher in the $\mathrm{F}_{4}$ SEG population $\left(F_{S T}=0.0125, \mathrm{P}<0.001\right.$, Table S3) than in the $\mathrm{F}_{4}$ INT population $\left(F_{S T}=0.0033\right.$, $\mathrm{P}<0.001)$. Divergence between the two hatchery lines in the $\mathrm{F}_{4}$ generation also continued to increase $\left(F_{S T}=0.0126, \mathrm{P}<\right.$ 0.001). Patterns of genetic change were further supported by a discriminant analysis of principal components, conducted on the first $63 \mathrm{PCs}$ as recommended by the optim.a.score function in adegenet. The segregated line diverged from the $\mathrm{P}_{1}$ founders and integrated line over time along the first discriminant function; this axis explained 59.2\% of the retained variation (Fig. 2). Genetic change between the later generations of the integrated line and the $\mathrm{P}_{1}$ founders was evident along the second discriminant function, which explained $16.6 \%$ of the retained variation.

Bias-adjusted LD and temporal estimates of effective number of breeders, $\mathrm{N}_{\mathrm{b}}$, supported earlier results and suggested that the relative effect of genetic drift was much greater in the segregated line than in the integrated line. The LD estimate of $\mathrm{N}_{\mathrm{b}}$ in the $\mathrm{F}_{4}$ INT population was nearly eight times higher than that obtained in the $\mathrm{F}_{4}$ SEG population (Fig. 3; 
Tables S4a, S5). The temporal $\mathrm{N}_{\mathrm{b}}$ estimates, which applied to the entire sampling period of 1998-2014, were also markedly different between the two lines (Fig. 3; Table S4b). While the average broodstock size of the integrated line $(363 \pm 15)$ exceeded that of the segregated line $(85 \pm 15)$, the difference was not sufficient to explain the higher $\mathrm{N}_{\mathrm{b}}$ of the integrated line (Table S6).

In addition, the $\mathrm{N}_{\mathrm{b}}$ estimates for the $\mathrm{F}_{4}$ generation revealed a result that was not apparent from the census data alone. The ratio of effective number of breeders to census size $\left(\mathrm{N}_{\mathrm{b}} / \mathrm{N}_{\text {census }}\right)$ declined from 0.21 (95\% CI: 0.20-0.23) in the $\mathrm{F}_{3}$ INT sample to 0.04 (95\% CI: 0.03-0.04) in the $\mathrm{F}_{4}$ INT sample, despite the fact that the census sizes increased from 3364 to 8374 adults. This result is important because the $\mathrm{N}_{b} / \mathrm{N}_{\text {census }}$ ratio provides a metric for understanding factors which cause deviations from $\mathrm{N}_{\mathrm{b}}=\mathrm{N}_{\text {census }}$ (e.g. variance in reproductive success) and affect genetic variation over time.

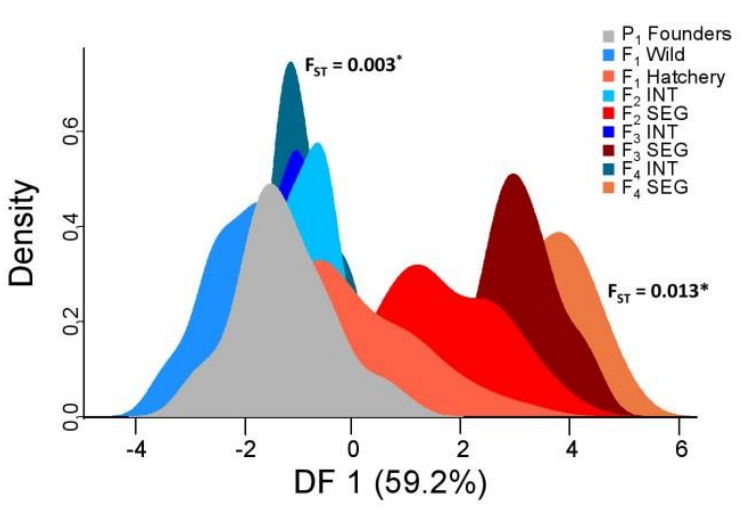

Figure 2. Density plot of individuals along the first discriminant function from the discriminant analysis of principal components (DAPC) for the wild founders $\left(\mathrm{P}_{1}\right.$ Founders, black) and four generations of the integrated (INT, blue colors) and segregated (SEG, red colors) hatchery lines. Pairwise $F_{S T}$ values for the $\mathrm{F}_{4}$ generation compared to the $\mathrm{P}_{1}$ founders are shown for each hatchery line.

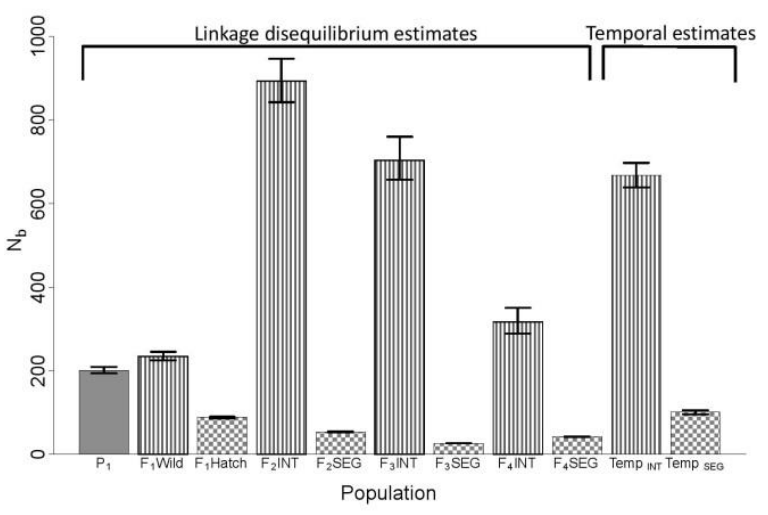

Figure 3. Estimates of effective number of breeders, $\mathrm{N}_{b}$, and $95 \%$ confidence intervals produced by the linkage disequilibrium (LD) and temporal methods. The LD method enables estimation of $\mathrm{N}_{\mathrm{b}}$ for every generation, while a single estimate for the sampling period is produced by the temporal method. LD estimates are adjusted for physical linkage and other potential biases as described in Waters et al. (2015).

Three independent tests identified loci and genomic regions that exhibited signals of diversifying selection. The $F_{T E M P}$ method identified 78 loci that exceeded neutral expectations in the integrated line and 198 in the segregated line (Table S7). Thirty-five loci were outliers in both hatchery lines. Bayescan, conducted using all populations combined, identified 120 loci putatively under diversifying selection (Table S7). There was considerable overlap between Bayescan and $\mathrm{F}_{\mathrm{TEMP}}$, as 48 and 72 Bayescan outliers were also identified by $F_{T E M P}$ in the integrated and segregated lines, respectively. Genomic regions that exhibited significantly elevated levels of divergence compared to the $\mathrm{P}_{1}$ founders were identified in both hatchery lines by sliding window analyses (Table S8). However, divergence in the segregated line was more consistent across the $\mathrm{F}_{1}, \mathrm{~F}_{2}, \mathrm{~F}_{3}$, and $\mathrm{F}_{4}$ generations than in the integrated line. For example, seven regions were significantly elevated in at least three generations of the segregated line while none were observed in the integrated line (e.g. Fig. 4). Five of these regions also contained outlier loci identified by $F_{T E M P}$ and Bayescan (Fig. 4), providing further support that selection likely due to continued exposure to the hatchery environment - has also contributed to the higher levels of divergence observed in the segregated line. Previous work has identified genes in such regions of overlap that may be targeted by selection in captivity (Waters et al. 2015).

\section{Discussion}

Here, we have demonstrated the utility of genomic-based methods to test alternative management approaches for population enhancement and to monitor fine scale genetic changes in populations over several generations. Many theoretical studies have indicated that ongoing gene flow between hatchery and wild fish may ultimately compromise the fitness of the natural population (Ford 2002; Baskett \& Waples 2013). However, the degree to which the natural population is affected depends on many factors that likely fluctuate over time, such as selection intensity, the proportion of wild-origin individuals on the spawning grounds, reproductive rate in the hatchery and wild, and carrying capacity of the natural system. Thus, our multigenerational findings extend complementary studies that evaluate reproductive success in single populations over one or two generations (Christie et al. 2014). The results from the fourth hatchery generation largely supported observations 
from a previously published longitudinal study (Waters et al. 2015). Little genetic change occurred in the integrated hatchery line, which frequently exchanged migrants with the founding wild population. In contrast, consistent temporal trends in divergence were documented in the segregated hatchery line, which is maintained as a closed population. Such consistency was observed on the population-level and at specific genomic regions, despite the fact that environmental change likely occurred during the sixteen years over which this study was conducted. This result might be explained by domestication selection imposed by the relatively uniform hatchery environment on the segregated hatchery population. Genomic regions exhibiting potential signals of domestication selection can be further examined to identify candidate genes (e.g. Waters et al. 2015) and mechanisms underlying genetic adaptation to captivity, and to inform management practices to possibly reduce this risk.

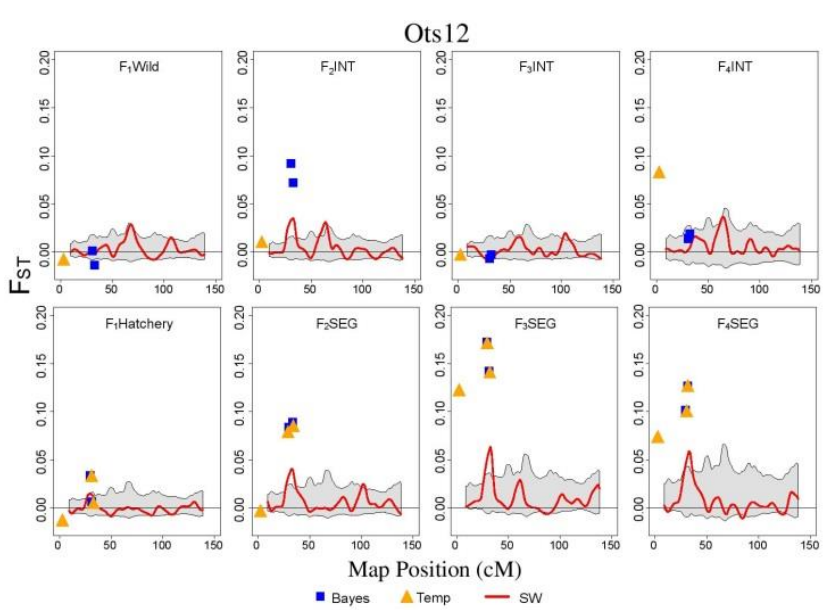

Figure 4. Loci and regions of the genome showing signatures of adaptive divergence, based on pairwise $F_{S T}$ compared to the $\mathrm{P}_{1}$ founders, on chromosome Ots12 for the integrated (top panel) and segregated (bottom panel) hatchery lines through the $F_{1}, F_{2}, F_{3}$, and $F_{4}$ generations. Blue squares are loci that were identified as outliers with Bayescan and orange triangles are outliers identified by $F_{T E M P}$. The red line represents the kernel smoothed moving average of $F_{S T}$ and the grey shaded area is the $95 \%$ confidence interval.

Notably, extending the earlier study by another generation also revealed fluctuations in $\mathrm{N}_{\mathrm{b}} / \mathrm{N}_{\text {census }}$ that would otherwise have been missed. We previously reported $\mathrm{N}_{\mathrm{b}} / \mathrm{N}_{\text {census }}$ ratios of 0.11 (95\% CI: 0.10-0.12) and 0.21 (95\% CI: $0.20-$ 0.23 ) for the $F_{2}$ and $F_{3}$ INT samples, respectively, which reflected the first two generations of naturally-spawning adults that included hatchery fish from the integrated line. These estimates show a positive trend in $\mathrm{N}_{\mathrm{b}} / \mathrm{N}_{\text {census }}$, which, if taken alone, could possibly be attributed to successful supplementation efforts. However, it is important to acknowledge temporal variability, and the decline of $\mathrm{N}_{b} / \mathrm{N}_{\text {census }}$ to 0.04 in the $\mathrm{F}_{4}$ INT sample may have two explanations. The first is that the results may indicate the influence of the Ryman-Laikre effect (Ryman \& Laikre 1991), where supportive breeding reduces the effective size of a wild population. Alternatively, temporal fluctuations in $\mathrm{N}_{\mathrm{b}} / \mathrm{N}_{\text {census }}$ could simply reflect changes in the natural environment that influence demographic factors; the observed ratios of 0.04-0.21 are within the range of those documented in natural populations of many species (including salmonids; Frankham 1995; Naish et al. 2013). It is impossible to identify the true source(s) of the observed fluctuations, particularly since there is no wild control population for comparison. Nevertheless, our results emphasize the importance of continued monitoring and the viability of integrating processes affecting the productivity of natural systems with enhancement efforts. Finally, while this study does not evaluate fitness directly and lacks an unsupplemented control population, rates of genetic divergence measured here provide a range of multigenerational outcomes for contrasting management regimes. These comparative findings, in turn, can assist managers and policy-makers when assessing the relative benefits and risks of conservation decisions, particularly in cases where population recovery may depend on supportive breeding.

Fisheries Genomics Work Funding Sources

Country-specific information (United States)

NOAA - National Sea Grant Program, Saltonstall-Kennedy, National Science Foundation, Bonneville Power / Federal Columbia River Power System (FCRPS) Biological Opinion Remand Funds, US Department of Agriculture

Funding sources accessed to support Genomics research

NOAA - National Sea Grant Program, Washington Sea Grant Program, National Science Foundation, Federal Columbia River Power System (FCRPS) Biological Opinion Remand Funds, US Department of Agriculture

\section{Examples of genetic/genomic information to inform fisheries management and/or policy decisions in USA}

Many of the listings under the Endangered Species Act rely on genetic information. Such data has been used to delineate "Distinct Population Segments" (Conservation Units) that are the subject of management actions. There are many publications associated with this activity, including reports. NOAA maintains a list of technical reports on this website: https://www.nwfsc.noaa.gov/publications/scipubs/displayinclude.cfm?incfile=technicalmemorandum2016.inc

The publications of interest are the "status reviews". The Hatchery Scientific Review Group on the West Coast of the USA has been extensively involved in developing "best practices" for the recovery and enhancement of salmon populations. http://www.hatcheryreform.us/hrp/welcome show.action. Many of the reforms are based on a wide number of papers that 
have been published on the impacts of hatchery fish on wild fish. Work in this area is also influencing the management of other fish species, as well as molluscan population management.

Mobrand, L. E., J. Barr, L. Blankenship, D. E. Campton, T. T. P. Evelyn, T. A. Flagg, C. V. W. Mahnken, L. W. Seeb, P. R. Seidel, and W. W. Smoker. 2005. Hatchery reform in Washington State: Principles and emerging issues. Fisheries 30:11-23.

Araki, H., B. Cooper, and M. S. Blouin. 2007. Genetic effects of captive breeding cause a rapid, cumulative fitness decline in the wild. Science 318:100-103.

Paquet, P. J., T. Flagg, A. Appleby, J. Barr, L. Blankenship, D. Campton, M. Delarm, T. Evelyn, D. Fast, J. Gislason, P. Kline, D. Maynard, L. Mobrand, G. Nandor, P. Seidel, and S. Smith. 2011. Hatcheries, Conservation, and Sustainable Fisheries-Achieving Multiple Goals: Results of the Hatchery Scientific Review Group's Columbia River Basin Review. Fisheries 36:547-561.

Seamons, T. R., L. Hauser, K. A. Naish, and T. P. Quinn. 2012. Can interbreeding of wild and artificially propagated animals be prevented by using broodstock selected for a divergent life history? Evolutionary Applications 5:705719.

Hess, M. A., C. D. Rabe, J. L. Vogel, J. J. Stephenson, D. D. Nelson, and S. R. Narum. 2012. Supportive breeding boosts natural population abundance with minimal negative impacts on fitness of a wild population of Chinook salmon. Molecular Ecology 21:5236-5250.

Waters, C. D., J. J. Hard, M. S. O. Brieuc, D. E. Fast, K. I. Warheit, R. S. Waples, C. M. Knudsen, W. J. Bosch, and K. A. Naish. 2015. Effectiveness of managed gene flow in reducing genetic divergence associated with captive breeding. Evolutionary Applications 8:956-971.

There is a growing interest in "parentage based tagging" (PBT) for tagging fish populations, which is viewed as an alternative for the coded wire tag program. PBT has significant potential to contribute to fisheries management.

Anderson, E. C., and J. C. Garza. 2006. The power of single-nucleotide polymorphisms for large-scale parentage inference. Genetics 172:2567-2582.

Campbell, N. R., S. A. Harmon, and S. R. Narum. 2015. Genotyping-in-Thousands by sequencing (GT-seq): A cost effective SNP genotyping method based on custom amplicon sequencing. Molecular Ecology Resources 15:855867.

Steele, C. A., E. C. Anderson, M. W. Ackerman, M. A. Hess, N. R. Campbell, S. R. Narum, and M. R. Campbell. 2013. A validation of parentage-based tagging using hatchery steelhead in the Snake River basin. Canadian Journal of Fisheries and Aquatic Sciences 70:1046-1054.

Molecular-based methods are used extensively for stock identification, mixed stock analysis and measures of abundance

Dann, T. H., C. Habicht, T. T. Baker, and J. E. Seeb. 2013. Exploiting genetic diversity to balance conservation and harvest of migratory salmon. Canadian Journal of Fisheries and Aquatic Sciences 70:785-793.

Hess, J. E., J. M. Whiteaker, J. K. Fryer, and S. R. Narum. 2014. Monitoring Stock-Specific Abundance, Run Timing, and Straying of Chinook Salmon in the Columbia River Using Genetic Stock Identification (GSI). North American Journal of Fisheries Management 34:184-201.

Satterthwaite, W. H., M. S. Mohr, M. R. O'Farrell, E. C. Anderson, M. A. Banks, S. J. Bates, M. R. Bellinger, L. A. Borgerson, E. D. Crandall, J. C. Garza, B. J. Kormos, P. W. Lawson, and M. L. Palmer-Zwahlen. 2014. Use of Genetic Stock Identification Data for Comparison of the Ocean Spatial Distribution, Size at Age, and Fishery Exposure of an Untagged Stock and Its Indicator: California Coastal versus Klamath River Chinook Salmon. Transactions of the American Fisheries Society 143:117-133.

\section{Acknowledgements}

We thank everyone who was involved in establishing CESRF, shaping its research direction, and sampling broodstock, including Levi George, Melvin Sampson, Steve Schroder, Craig Busack, past and present members of the Independent Scientific Review Panel, and the Yakama Nation Tribal Council. We are grateful to Maren Wellenreuther and Louis Bernatchez, and the OECD Co-operative Research Programme for the opportunity to present this research at the World Fisheries Congress in Korea. Funding for this study was provided by NOAA Fisheries/Federal Columbia River Power System (FCRPS) Biological Opinion Remand Funds (to K.A.N. and J.J.H.), Washington Sea Grant (Award NA14OAR4170078 to K.A.N), and the Hall Conservation Genetics Research Award from the University of Washington (to C.D.W.).

\section{Literature Cited}

Baird NA, Etter PD, Atwood TS, et al. (2008) Rapid SNP discovery and genetic mapping using sequenced RAD markers. Plos One 3, 7. 
Baskett ML, Waples RS (2013) Evaluating alternative strategies for minimizing unintended fitness consequences of cultured individuals on wild populations. Conservation Biology 27, 83-94.

Beamish RJ, Sweeting RM, Lange KL, et al. (2010) Early Marine Survival of Coho Salmon in the Strait of Georgia Declines to Very Low Levels. Marine and Coastal Fisheries 2, 424-439.

Brieuc MSO, Ono K, Drinan DP, Naish KA (2015) Integration of Random Forest with population-based outlier analyses provides insight on the genomic basis and evolution of run timing in Chinook salmon (Oncorhynchus tshawytscha). Molecular Ecology 24, 2729-2746.

Brieuc MSO, Waters CD, Seeb JE, Naish KA (2014) A dense linkage map for Chinook salmon (Oncorhynchus tshawytscha) reveals variable chromosomal divergence after an ancestral whole genome duplication event. G3Genes Genomes Genetics 4, 447-460.

Christie MR, Ford MJ, Blouin MS (2014) On the reproductive success of early-generation hatchery fish in the wild. Evolutionary Applications 7, 883-896.

Do C, Waples RS, Peel D, et al. (2014) $\mathrm{N}_{\mathrm{E}}$ ESTIMATOR v2: re-implementation of software for the estimation of contemporary effective population size $\left(\mathrm{N}_{\mathrm{e}}\right)$ from genetic data. Molecular Ecology Resources 14, 209-214.

Duschene P, Bernatchez L (2002) An analytical investigation of the dynamics of inbreeding in multi-generation supportive breeding. Conservation Genetics 3, 45-58.

Foll M, Gaggiotti O (2008) A genome-scan method to identify selected loci appropriate for both dominant and codominant markers: a Bayesian perspective. Genetics 180, 977-993.

Ford MJ (2002) Selection in captivity during supportive breeding may reduce fitness in the wild. Conservation Biology 16, 815-825.

Frankham R (1995) Effective population size/adult population size ratios in wildlife: a review. Genetical Research 66, 95107.

Jombart T (2008) adegenet: a R package for the multivariate analysis of genetic markers. Bioinformatics 24, 1403-1405.

Laikre L, Schwartz MK, Waples RS, Ryman N, GeM_Working_Group (2010) Compromising genetic diversity in the wild: unmonitored large-scale release of plants and animals. Trends in Ecology \& Evolution 25, 520-529.

Lorenzen K, Leber KM, Blankenship HL (2010) Responsible Approach to Marine Stock Enhancement: An Update. Reviews in Fisheries Science 18, 189-210.

Mobrand LE, Barr J, Blankenship L, et al. (2005) Hatchery reform in Washington state: Principles and emerging issues. Fisheries 30, 11-23.

Naish KA, Seamons TR, Dauer MB, Hauser L, Quinn TP (2013) Relationship between effective population size, inbreeding and adult fitness-related traits in a steelhead (Oncorhynchus mykiss) population released in the wild. Molecular Ecology 22, 1295-1309.

Naish KA, Taylor JE, Levin PS, et al. (2008) An evaluation of the effects of conservation and fishery enhancement hatcheries on wild populations of salmon. Advances in Marine Biology 53, 61-194.

Paquet PJ, Flagg T, Appleby A, et al. (2011) Hatcheries, Conservation, and Sustainable Fisheries-Achieving Multiple Goals: Results of the Hatchery Scientific Review Group's Columbia River Basin Review Fisheries 36, 547-561.

Raymond M, Rousset F (1995) Genepop (version 1.2) - Population-genetics software for exact tests and ecumenicism. Journal of Heredity 86, 248-249.

Ryman N, Laikre L (1991) Effects of supportive breeding on the genetically effective population size. Conservation Biology 5, 325-329.

Scheuerell MD, Buhle ER, Semmens BX, et al. (2015) Analyzing large-scale conservation interventions with Bayesian hierarchical models: a case study of supplementing threatened Pacific salmon. Ecology and Evolution 5, 21152125.

Storey JD (2002) A direct approach to false discovery rates. Journal of the Royal Statistical Society Series B-Statistical Methodology 64, 479-498.

Therkildsen NO, Hemmer-Hansen J, Als TD, et al. (2013) Microevolution in time and space: SNP analysis of historical DNA reveals dynamic signatures of selection in Atlantic cod. Molecular Ecology 22, 2424-2440.

Waters CD, Hard JJ, Brieuc MSO, et al. (2015) Effectiveness of managed gene flow in reducing genetic divergence associated with captive breeding. Evolutionary Applications 8, 956-971. 